\title{
Quantitative Risk Analysis of a Rainfall-Induced Complex Landslide in Wanzhou County, Three Gorges Reservoir, China
}

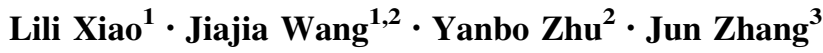

Published online: 4 March 2020

(C) The Author(s) 2020

\begin{abstract}
On 4 April 2013, a 1.5 million cubic meter landslide occurred in Sunjia Town, Wanzhou County, Three Gorges Reservoir, China. After initiation, the Sunjia landslide traveled about $30 \mathrm{~m}$ toward the northeast and destroyed most of the infrastructure in its path. The landslide was triggered by heavy rainfall and previous slope excavations, but this slope also displayed a complicated failure process: the overlying earth slope first deformed and then induced sliding along underlying rock surfaces. Surface displacements that resulted from continuous creeping of the post-event slope were observed by an emergency monitoring system that revealed the disequilibrium state of the slope. To discuss the stability and future movements of the remaining unstable debris deposits, we developed a geotechnical model of the post-slide slope, calculated how it can slide again in an extreme rainfall scenario, and estimated the potential runout distance using the Tsunami Squares method. We then estimated the number of people and the value of the infrastructure threatened by this potential landslide. Lastly, we analyzed the vulnerability of elements at risk and quantitatively evaluated the hazard risk associated with the most dangerous scenario. This quantitative risk analysis provides a better understanding of, and technical routes for, hazard mitigation of rainfallinduced complex landslides.
\end{abstract}

\section{Jiajia Wang}

jwang@chd.edu.cn

1 School of Highway, Chang'an University, Xi' an 710064, China

2 School of Geological Engineering and Geomatics, Chang'an University, Xi'an 710064, China

3 Tunnel and Underground Engineering Research Center of Jiangsu Province, Nanjing 210041, China
Keywords China - Hazard mitigation · Quantitative risk analysis · Rainfall-induced landslides · Runout simulation - Slope stability - Three Gorges Reservoir

\section{Introduction}

Rainfall-induced complex landslides often exhibit characteristics of progressive deformation and failure, and threaten people's lives and properties all over the world (Baum and Godt 2010; Martha et al. 2015; Bignami et al. 2018; Conte et al. 2018). Rainfall infiltration increases pore pressure, which in turn decreases the effective stress in the soil and reduces the soil shear strength, eventually resulting in slope failure (Xu et al. 2012; Duc 2013; Conte et al. 2017). Adverse geological conditions and human activities may exacerbate hazardous situations (Xu et al. 2018). Complex landslides are defined as those having multifarious material components, motion styles and mechanisms, and need to be studied both from the geomorphological and geological perspectives in order to recognize the corresponding failure mechanisms, which are the critical points that enable evaluation of future hazard risk posed by complex, rainfall-induced landslides (Sabatakakis et al. 2005; Lin et al. 2018).

Risk analysis is an effective measure for hazard prevention and mitigation of rainfall-induced landslides (Dai et al. 2002; Glade et al. 2005; Fell et al. 2008). The framework of landslide risk analysis is relatively well-developed and applications to rainfall-induced landslides are commonly carried out by researchers worldwide (Cascini et al. 2013; Andersson-Skold and Nyberg 2016). Landslide risk assessment can be classified into three categories based on the map-scale of the study area: (1) For large-scale 
areas, regional landslide susceptibility assessments using statistical methods and landslide hazard evaluation based on magnitude-frequency distribution approaches are the main technical routes to carry out semiquantitative risk assessment (Malamud et al. 2004); (2) For field-scale areas, deterministic models are often applied to calculate slope stability and landslide intensity in consideration of triggering factors such as rainfall and earthquake shaking with a specific return period (Iverson 2000; Baum and Godt. 2010); and (3) For individual landslides, risk assessment is still difficult and rarely seen in the literature because it involves myriad aspects such as hazard probability, landslide intensity, vulnerability, and the value of elements at risk (Westen et al. 2006; Westen et al. 2008). Generally, landslide hazard probability is studied by analyzing the return period of specific triggering events combined with the failure probabilities of a specific slope given an intensity and magnitude (Guzzetti et al. 2006). Many numerical methods for landslide runout modeling have been proposed in recent decades, such as DAN3D (Hungr and McDougall 2009), LS-RAPID (Sassa et al. 2010), MassFlow (Ouyang et al. 2013), and Tsunami Squares (Wang et al. 2015, 2019; Xiao et al. 2015; Xiao et al. 2018).

In view of these considerations, landslide hazard analysis needs to take into account the intensity of each landslide, which can be defined in terms of its volume and sliding velocity (Fell 1994). Moreover, to calculate landslide risk the spatial and temporal probability of occurrence of damaging events, the distribution of the elements at risk in space and time, and their changing vulnerabilities, all must be determined (Bell and Glade 2004; Ndah and Odihi 2017). Although various methods to carry out quantitative landslide risk analyses are available, applications are still rare and mostly depend on the occurrence of disasters. For individual landslides, the appropriateness and efficiency of those methods should be investigated carefully in regard to uncertainties and deviations in landslide risk calculation. Precise knowledge of historical rainfall, rock and soil parameters, dynamic friction coefficients, and values of elements at risk are required to develop an acceptable risk calculation. All of these factors create difficulties in risk assessment of individual landslides. Hence, it is of great significance to perform quantitative risk assessment of well-observed and data-rich cases to further establish the framework of risk analysis of rainfall-induced landslides (Cascini 2008; Calvello et al. 2009).

The 1.5 million cubic meter Sunjia landslide occurred on 4 April 2013 in Wanzhou County, Three Gorges Reservoir, China. This landslide had a horizontal travel distance about $30 \mathrm{~m}$ and destroyed all the infrastructure (roads, terraces, houses) it encountered. In addition, the post-slide deposits of this landslide remain unstable and constitute a continuing hazard to the lives and properties of downslope inhabitants. Therefore, a comprehensive investigation and quantitative risk analysis of this landslide are urgently needed for the hazard prevention of this and other rainfall-induced landslides. In this study, we introduce the geomorphology and geological characteristics of the preand post-slide Sunjia slope based on field and drilling surveys. We also analyze the current stability state of the post-slide slope based on post-event emergency monitoring of surface displacement. To discuss the potential risk, we develop a geotechnical model of the landslide, calculate its failure probability, and simulate the potential run out distance using the Tsunami Squares method (Wang et al. 2015; Xiao et al. 2015). Combining these results, we evaluate the potential risk of this slope based on a detailed investigation of the endangered elements.

\section{The 2013 Sunjia Landslide}

The Sunjia landslide occurred in Wanzhou County, in the Three Gorges Reservoir region, an area considered one of the most landslide-prone in China. In order to quantify the hazard risk of this landslide, we proposed a summary research on the background of the pre-slide slope and current state of the post-slide slope in the sections below based on our previous field investigations.

\subsection{Overview of the Event}

Sunjia Town, in western Wanzhou County (Fig. 1a), suffered a $1.5 \times 10^{6} \mathrm{~m}^{3}$ landslide at about 13:15 on 4 April 2013 (local time). The source slope of the landslide initiated in a low to middle elevation mountainous region with a slope inclination of $5^{\circ}$ and a slope angle of $20^{\circ}-35^{\circ}$. Destablized by abundant rainfall, the Sunjia slope experienced progressive incipient failure 1 day prior to the eventual landslide that slid downslope about $30 \mathrm{~m}$ toward the northeast with catastrophic consequences for most of the infrastructure along its trajectory (Fig. 1b). Thanks to the local government's geohazards measurement and prevention group, the residents on the landslide path were given an early warning and evacuated before the disaster. As a result no fatalities or injuries occurred on the slope. But the deposits on the post-slide slope remain unstable, and continue to pose a threat to people's lives and public infrastructures, such as the Yuwan national expressway further down the slope.

\subsection{Landslide Geometric and Geological Conditions}

The investigated landslide boundary (Figs. 1b, 2, red line) revealed a long tongue-shaped outline of the pre-landslide slope with a length of $\sim 550 \mathrm{~m}$ and an average width 

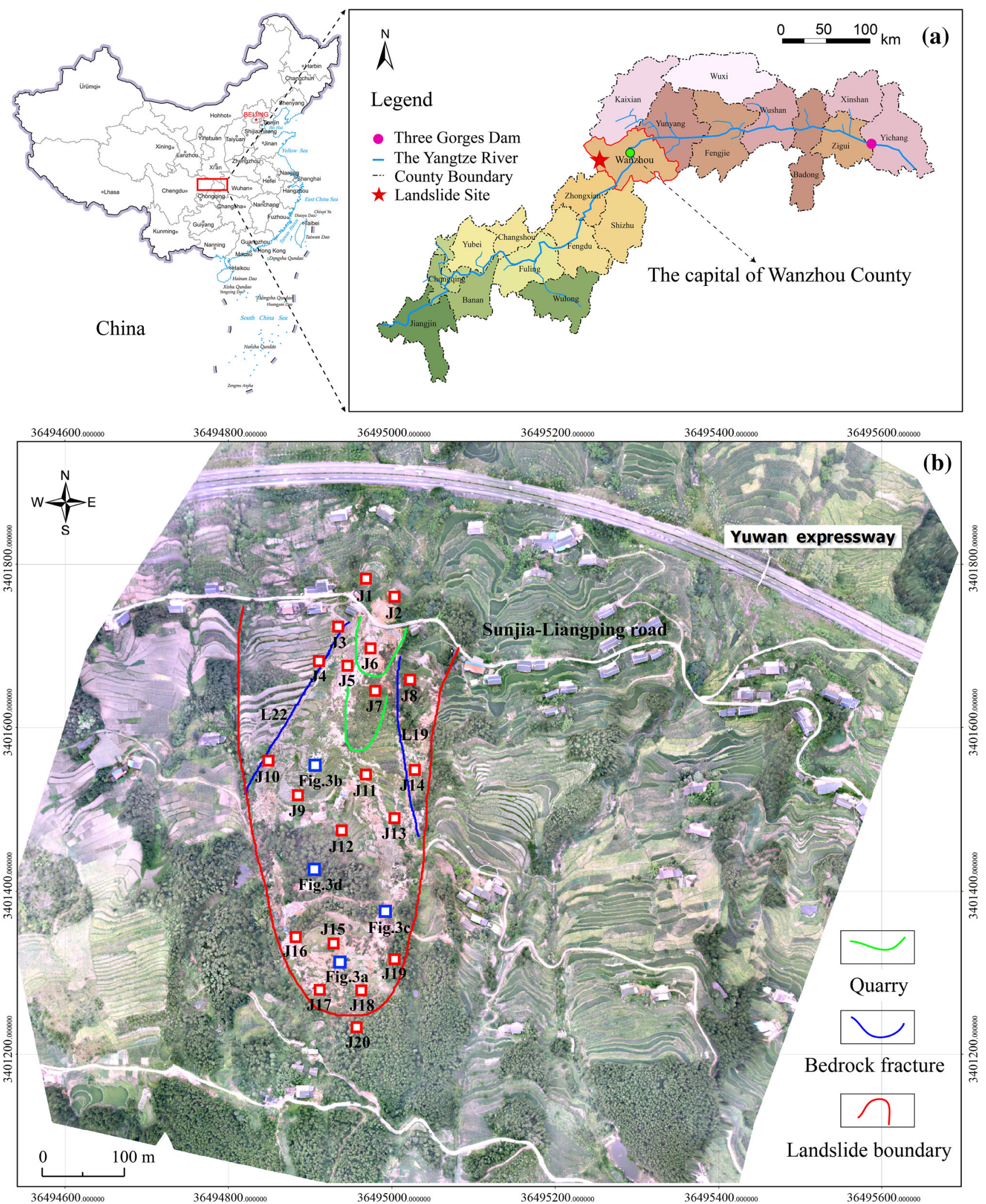

Fig. 1 Location of the Sunjia landslide, Wanzhou County, Three Gorges Reservoir, China. a Administrative map of the Three Gorges Reservoir region, China. b An aerial image of the post-slide Sunjia slope provided by the Nanjiang Hydrogeological Engineering
Geological Team. The red squares point out the locations of the monitoring stations, and the blue squares indicate the sites of the photos shown in Fig. 3 Source Modified from Wang et al. (2020) 
of $\sim 240 \mathrm{~m}$. As shown in Fig. 2, the landslide cut out near the Sunjia-Liangping road at an elevation of $787 \mathrm{~m}$ to $800 \mathrm{~m}$ a.s.l. (above sea level), while its headscarp surfaced at an elevation of $960 \mathrm{~m}$ to $962 \mathrm{~m}$ a.s.l. close to a country road. On each side of the landslide, a N-S orientated gully (5-10 $\mathrm{m}$ in depth, 4-9 $\mathrm{m}$ in width, and $\sim 1500 \mathrm{~m}$ in length) cut through the slope, which could have affected the trajectory of the landslide (Figs. 1b, 2). At the slope toe, a two-stage slope cut formed by an abandoned quarry $\left(1500 \mathrm{~m}^{3}\right)$ and a slope excavation $\left(2000 \mathrm{~m}^{3}\right)$ may also have had adverse effects on slope stability (Fig. 2).

A post-slide drilling survey indicated that the lithology of the Sunjia slope was composed of an overlying Quaternary-Holocene accumulation of eluvium silty clay $\left(\mathrm{Q}_{4}^{\mathrm{el}+\mathrm{dl}}\right)$, a landslide accumulation $\left(\mathrm{Q}^{\mathrm{del}}\right)$, and the underlying bedrock of the Xintiangou Formation of the Lower
Jurassic $\left(\mathbf{J}_{2 \mathrm{x}}\right)$ (Wang et al. 2020, p. 423). The structure of the pre-slide slope is complex and comprises an overlying earth slope in contact with an underlying bedding rock slope. The upper-earth slope with an impermeable shale bedrock beneath on an unconsolidated layer is conducive to rainfall infiltration and subterranean storage. The lower flysch bedding rockslide, with a hard sandstone rock on the top and a strongly weathered, underlying shale rock is also sensitive to water infiltration. The Sunjia landslide was caused by both the slope excavations and heavy rainfall and exhibited a complicated failure progress in which the overlying earth slope first deformed and then induced the underlying rock to slide along the weak intercalated layers (Wang et al. 2020).
Fig. 2 Geomorphic map of the 2013 Sunjia landslide site in Wanzhou County. The blue dots represent the locations of the boreholes and the black numbers mark the elevation of the altimetric points. The grey double-lined polygons reveal the damaged rural roads Source Wang et al. (2020)

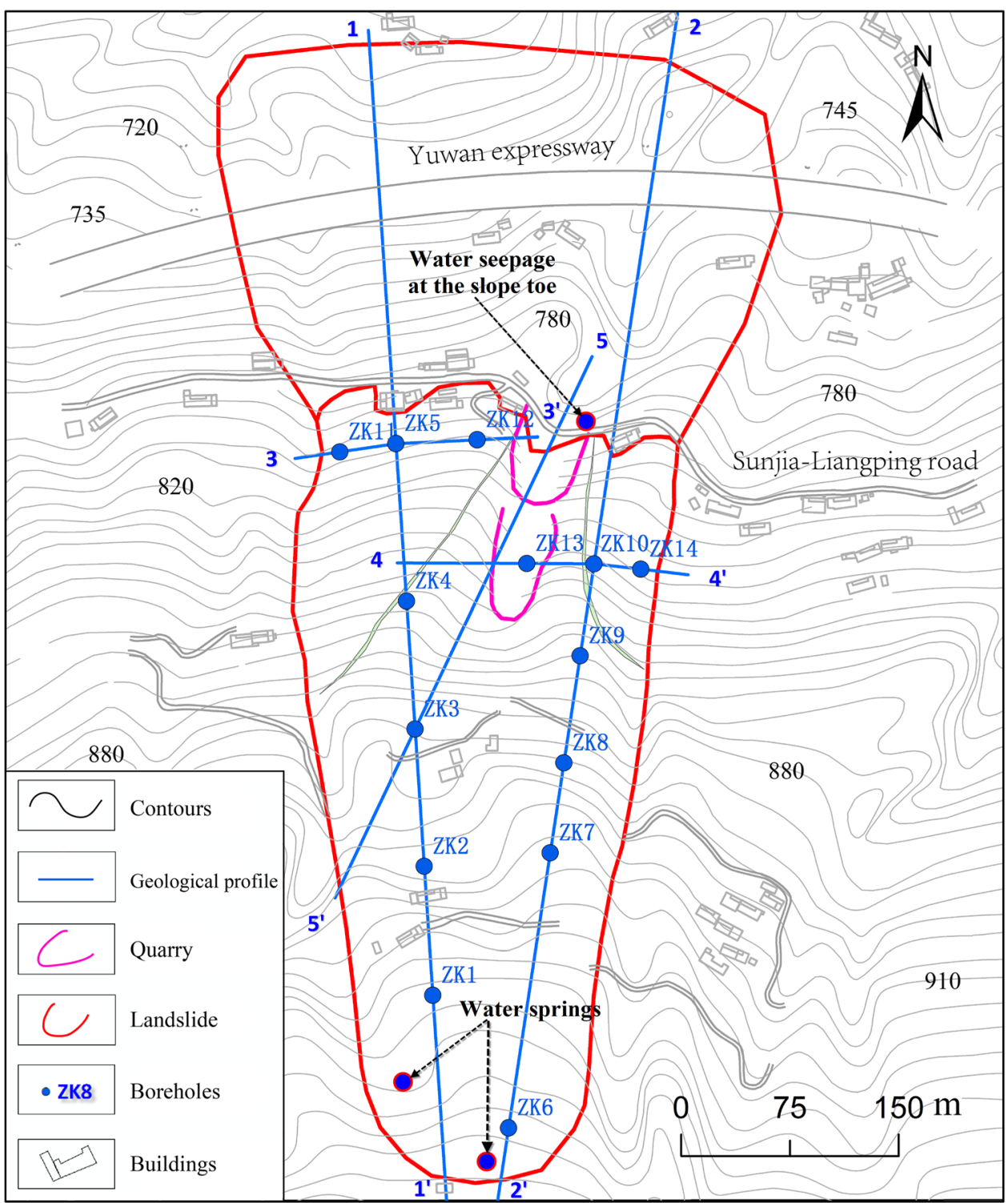




\subsection{The Current State of the Post-Slide Slope}

Post-event surveys show that the previous topography has changed due to the long-distance slip of the landslide, which generated large amounts of cracks, fissures, and infrastructure collapse (Fig. 3). To identify continuing surface displacement on the post-slide slope, emergency monitoring using Total Stations was implemented by the Nanjiang Hydrogeological Engineering Geological Team from 12 April to 31 August 2013 (Fig. 4, locations of the monitoring stations are marked in Fig. 1b). Minor surface displacements were observed outside of the front edge of the post-slide slope (Fig. 4, locations J1 and J2) indicating a relatively stable state downslope at the landslide toe. The average surface displacement during the monitoring period was about $40 \mathrm{~mm}$ at the front accumulation area with the displacements increasing from both edges to the middle of this area (Fig. 4, location J3 to J8). Influenced by the fractures in the middle of the slope (Fig. 1b), surface displacements up to $100 \mathrm{~mm}$ at the right side (righthand gully,
Fig. 4, locations J14) were relatively larger than those at the left side (drum hill, Fig. 4, locations J9 to J14). At the back margin of the landslide, the continuous deformation and collapse at the steep edges of the tensile groove led to an average surface displacement of about $40 \mathrm{~mm}$ (Fig. 4, locations J15 to J19). The area at the outside of the back margin of the post-slide slope also exhibited an unstable state with over $20 \mathrm{~mm}$ of surface displacement (Fig. 4, location J20). The surface displacements of the post-slide slope were controlled by the characteristics of the previous landslide movements and the geomorphic and geologic conditions of the post-slide slope.

\section{Post-Landslide Risk Assessment}

The monitoring data show an average cumulative displacement of about $36.4 \mathrm{~mm}$ on the post-slide slope from the day of the slope failure (4 April) to 31 August 2013 (Fig. 4). Taking into account the field investigation and
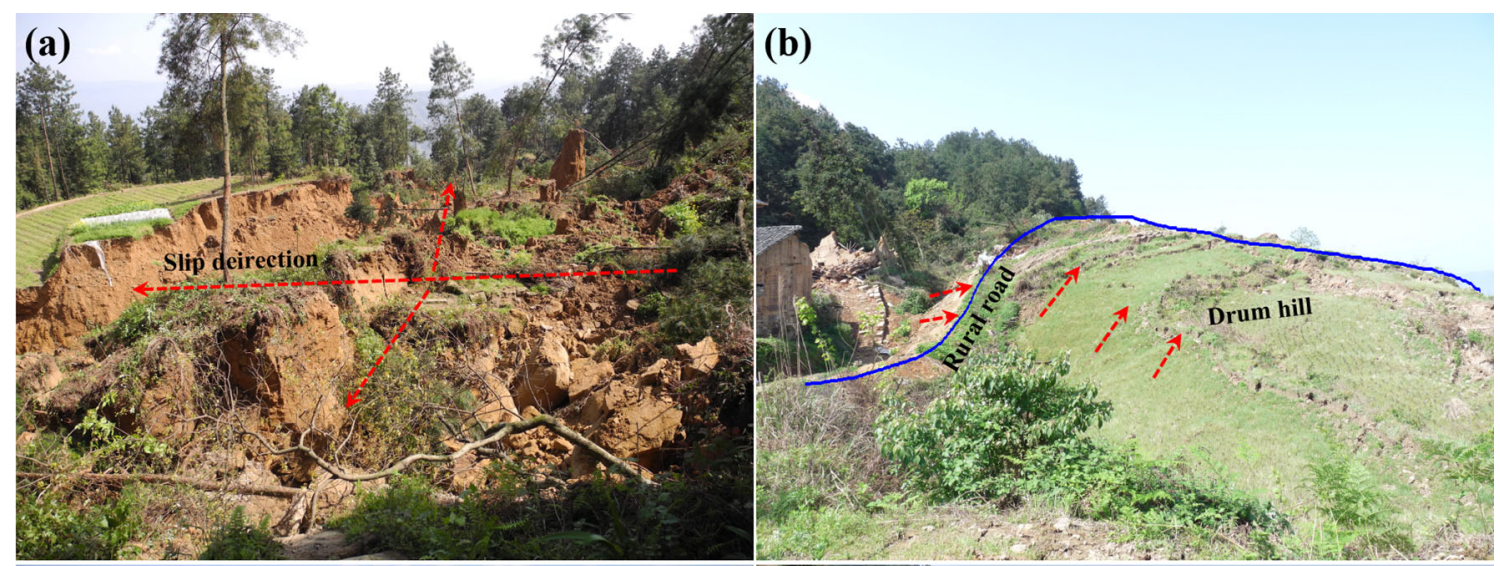

(c)

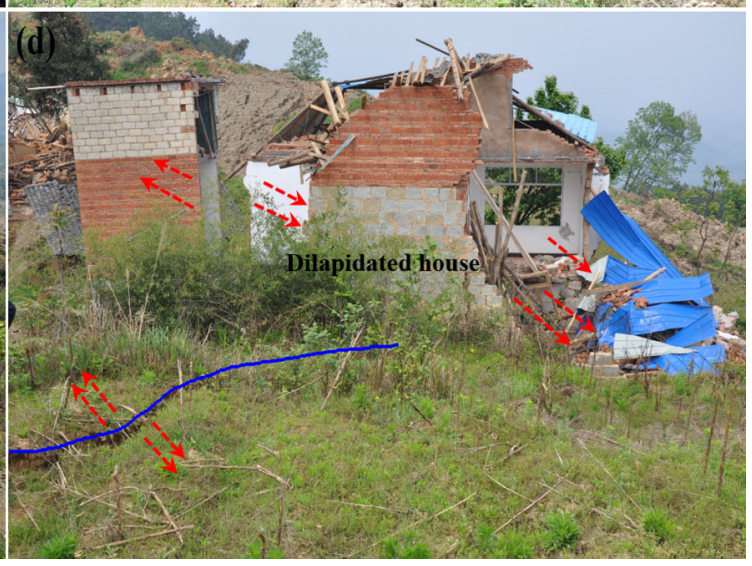

Fig. 3 Photographs showing the characteristics of landslide deformation at the 2013 Sunjia landslide site. a The tensile groove; b The drum hill; $\mathbf{c}$ The damaged rural road; $\mathbf{d}$ The dilapidated houses. The red dashed lines and arrows indicate the direction of surface

displacements and the blue lines indicate the specific microtopography. The blue squares in Fig. 1b represent the locations of the photos taken by the authors on 5 April 2013. Source Modified from Wang et al. (2020) 


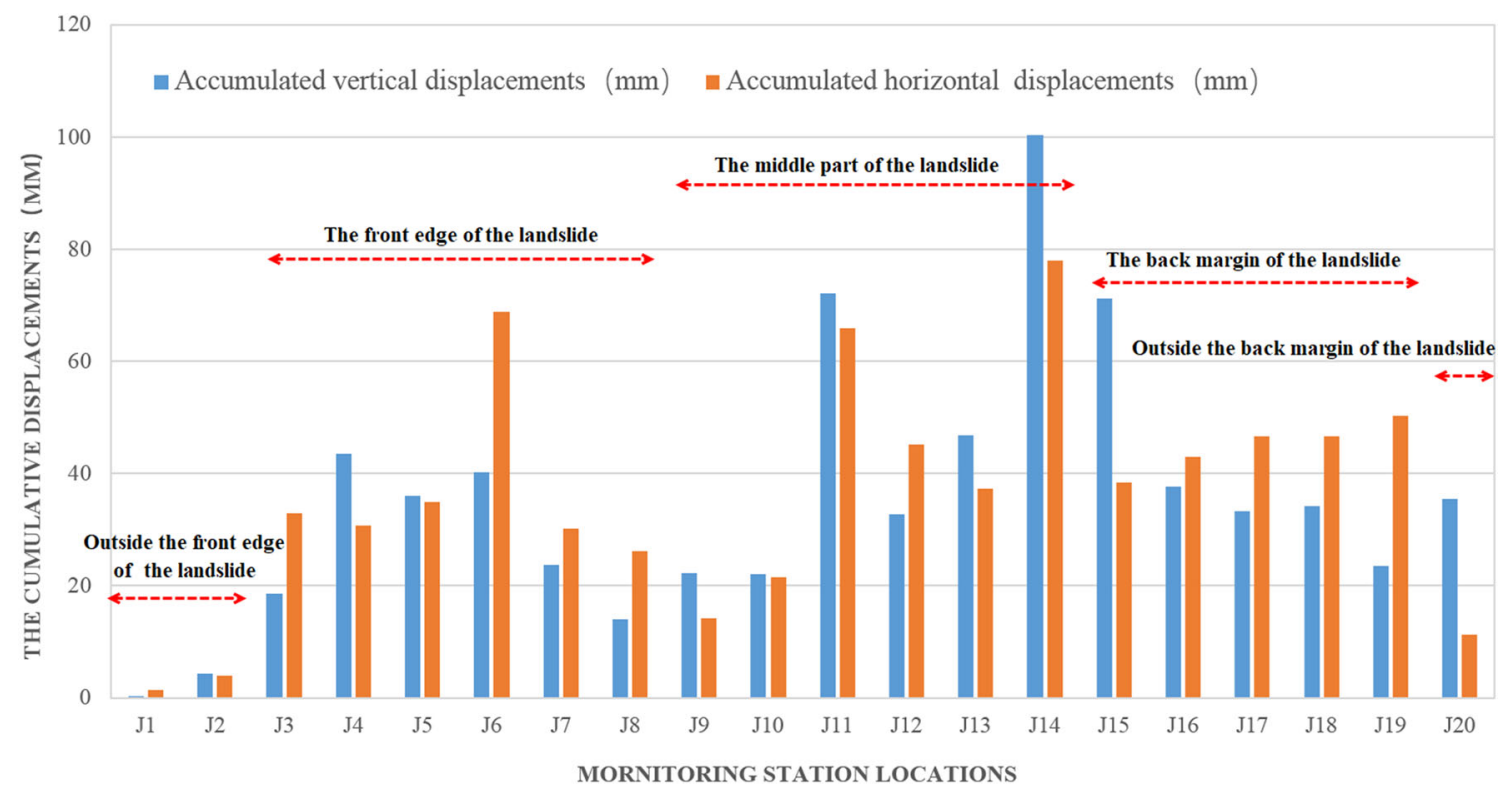

Fig. 4 Emergency monitoring at the surface of the 2013 Sunjia landslide in Wanzhou County from 5 April to 31 August 2013. The locations of the monitoring stations are marked by red squares in Fig. 1b

drilling survey, it can be concluded that the post-slide deposits of gravel soil and broken rock with a volume of about $1.0 \times 10^{6} \mathrm{~m}^{3}$ still remain unstable. Possibly a heavy rainfall could induce a secondary slope failure that would directly threaten people's lives and the Yuwan expressway downslope. Such conditions warrant an expanded discussion of the post-slide hazards, including temporal probability (failure probability), spatial probability (landslide runout modeling), and landslide risk assessment.

\subsection{Post-Landslide Hazard Analysis-Temporal Probability}

Landslide temporal probability describes the likelihood of an event with a certain intensity happening within a given period of time. For rainfall-induced landslides, slope stabilities and failure probabilities vary with the distribution of extreme rainfall. Generally, landslide temporal probability is studied by analyzing the return period (or probability) of extreme rainfall events and its related slope stabilities and failure probabilities (Beguería and VicenteSerrano 2006).

\subsubsection{Distribution of Extreme Rainfall}

The stability calculation of rainfall-induced landslides is sensitive to the selection of various rainfall types (intensity, duration) (Floris and Bozzano 2008). Annual maximum rainfall is a commonly used metric for selecting extreme rainfall types based on historical data, such as maximum daily rainfall, maximum rainfall for days, maximum continuous rainfall, and longest continuous rainfall (Deb and El-Kadi 2009).

Rainfall in the study area is abundant and synchronous with seasonal temperature. During 1964-2013, the average and maximum annual precipitation were $1191.3 \mathrm{~mm}$ and $1635.2 \mathrm{~mm}$, respectively. The historical data also record the maximum daily rainfall to be $243.31 \mathrm{~mm}$ (16 July 1982) and the average continuous rainfall duration to be 10 days (Fig. 5; Wang 2015). Based on the statistical analysis of the 50-year (1964-2013) rainfall records in the Wanzhou County, we chose maximum rainfall for 10-days as the most serious scenario in our models of triggered landslides.

The frequency distribution of extreme rainfall can be represented by a variety of mathematical curves with parameters estimated according to statistical principles. The tails of the calculated distribution can be used to extend predictions to very rare events. We employ a Gumbel distribution (Yue 2001) to calculate the distribution of extreme rainfall over different periods. The Gumbel distribution is obtained from a limit distribution law and its probability distribution is skewed. The density function form of the Gumbel distribution is:

$F(x)=P(\xi<x)=e^{-e^{-a(x-u)}}(a>0,-\infty<u<\infty)$

where $a$ is the scale parameter, and $u$ is the distributed density parameter. The Gumbel method estimates the two parameters as: 


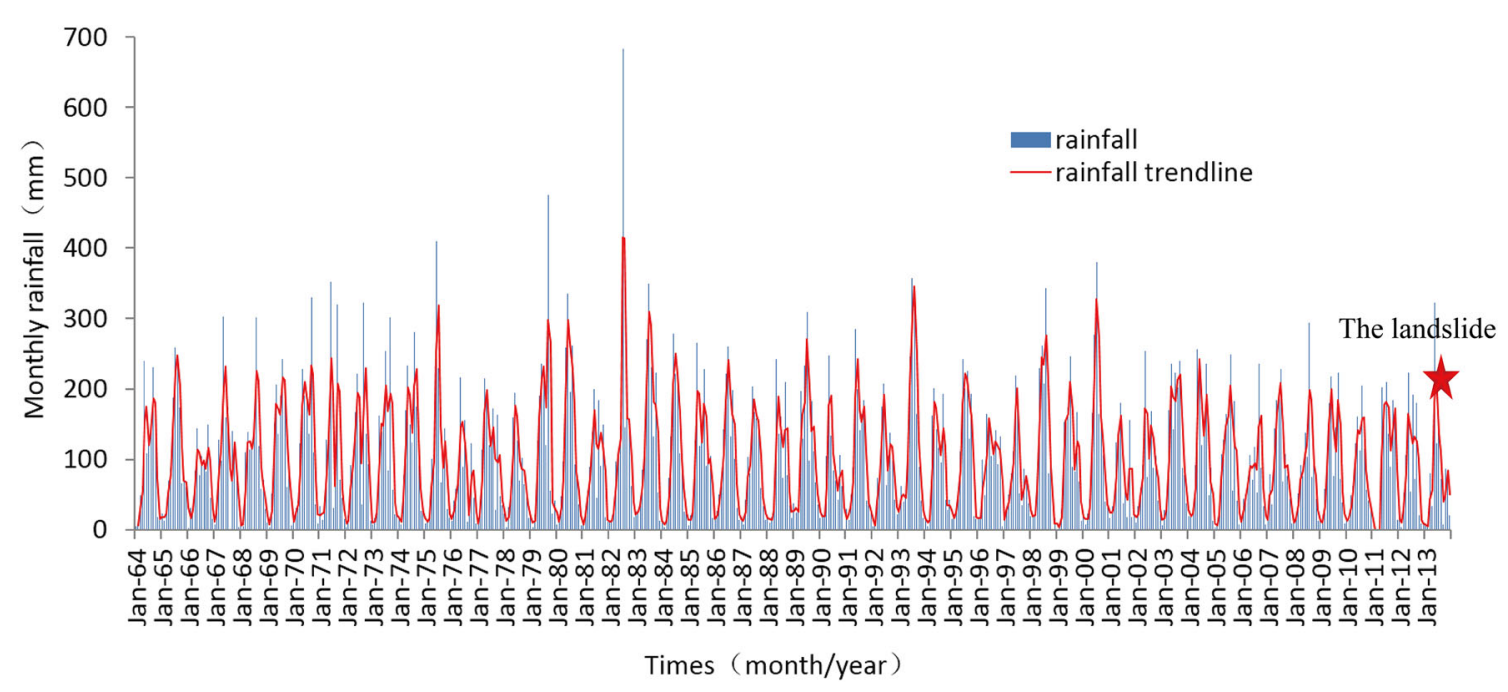

Fig. 5 Bi-monthly rainfall in Wanzhou County in 1964-2013, Three Gorges Reservoir region (data collected from the Wanzhou Geological Environment Monitoring Station). The red star indicates the time when landslide occurred

$\hat{a}=\frac{\sigma_{N}}{\sigma_{x}}, \quad \hat{u}=\bar{x}-\hat{a} \bar{y}_{N}$

where $\sigma_{x}$ is the standard deviation of the sample data, and $\sigma_{N}$ and $\bar{y}_{N}$ can be calculated by the equations below.

$\sigma_{N}=\sqrt{\frac{\sum\left(y_{m}-\bar{y}_{N}\right)^{2}}{N}}, \quad \bar{y}_{N}=\frac{\sum y_{m}}{N}$

$y_{m}=-\ln \left(-\ln \frac{m}{N+1}\right), \quad m=1,2, \ldots N$

By integrating Eq. 1, the cumulative probability of a random variable $\xi$ exceeding $x$ is

$F_{P}(x)=P(\xi \geq x)=1-e^{-e^{-a(x-u)}}$

Conversely, if the probability $P$ of a certain extreme rainfall is given, the intensity of the corresponding extreme rainfall under this condition $R_{P}$ can be solved (Eq. 6).

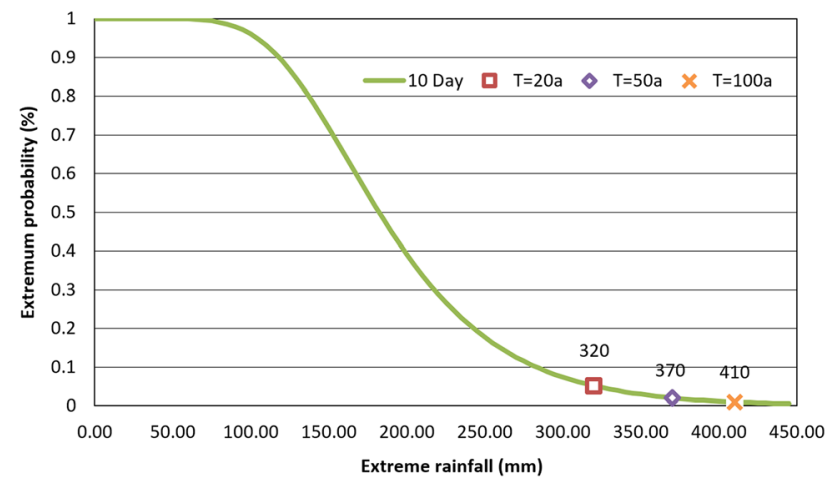

Fig. 6 Distribution of extreme rainfall over a 10-day duration with different return periods for Wanzhou County, Three Gorges Reservoir region. The scale parameter $a=0.02$ and the distributed density parameter $u=162.7$ in this case
Similarly, given the recurrence period $T$ of a certain extreme rainfall condition, the intensity $R_{T}$ of extreme rainfall occurring in that period can be solved (Eq. 7).

$$
\begin{aligned}
& R_{P}=u-\frac{1}{a}\left[\ln \ln \left(\frac{1}{1-P}\right)\right] \\
& R_{T}=u-\frac{1}{a}\left[\ln \ln \left(\frac{T}{T-1}\right)\right]
\end{aligned}
$$

By adopting the Gumbel distribution law, we calculated the parameters $a=0.02$ and $u=162.7$ for 10 -day rainfall based on the historical rainfall records and obtained the potential extreme rainfall in the study area (Fig. 6). The extreme rainfall over a 10-day period with return periods of 20 years, 50 years, and 100 years amounts to $320 \mathrm{~mm}$, $370 \mathrm{~mm}$, and $410 \mathrm{~mm}$, respectively.

\subsubsection{Analysis of Slope Stability and Failure Probability}

Most likely, the main sliding direction of the potential secondary slope failure will be along section $5-5^{\prime}$ (Figs. 2, 7) because most of the landslide deposits are distributed in this region and their boundaries are controlled by fractures L19 and L22 (Fig. 1b). Therefore, we constructed a geomechanical model of the post-slide slope using the software tool Geo-Studio (Krahn 2008a, 2008b) to evaluate the slope stability and failure probability on the basis of this profile.

According to laboratory test results (Wang 2015), we derived the physical and mechanical parameters of the rock and soil mass of the slope as listed in Table 1.

Four scenarios were considered in the slope-stability calculations based on the extreme rainfall distribution presented in Fig. 6: 
Fig. 7 Geological profile 5-5' of the 2013 Sunjia landslide in Wanzhou County. The location of the profile is shown in Fig. 2 Source Wang et al. (2020)

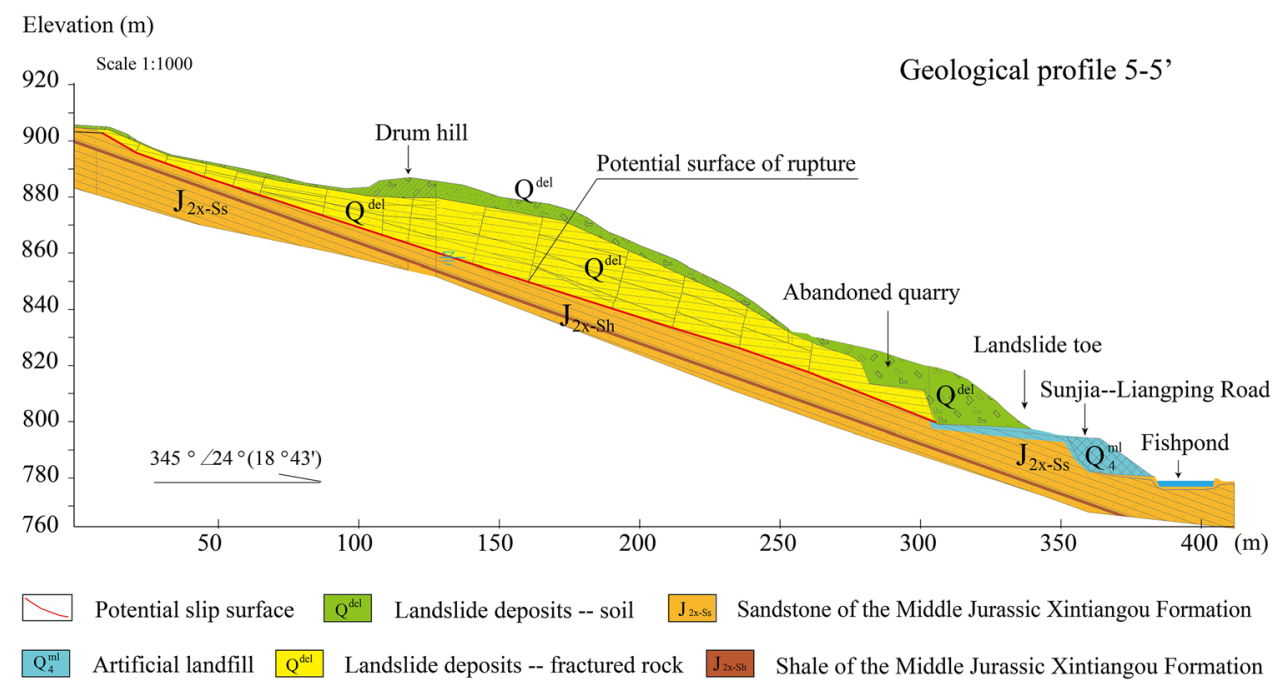

Table 1 Values of the physical and mechanical indices of the slope's bedding layers. c: Cohesion, Ф: angle of shearing resistance Source Wang (2015)

\begin{tabular}{|c|c|c|c|c|c|c|c|c|}
\hline \multirow[t]{3}{*}{$\begin{array}{l}\text { Composition of the slope's } \\
\text { bedding layers }\end{array}$} & \multirow[t]{3}{*}{$\begin{array}{l}\text { Natural unit } \\
\text { weight }\left(\mathrm{kN} / \mathrm{m}^{3}\right)\end{array}$} & \multirow[t]{3}{*}{$\begin{array}{l}\text { Saturated unit } \\
\text { weight }\left(\mathrm{kN} / \mathrm{m}^{3}\right)\end{array}$} & \multirow[t]{3}{*}{$\begin{array}{l}\text { Saturated volume } \\
\text { contains water }(\%)\end{array}$} & \multirow[t]{3}{*}{$\begin{array}{l}\text { Saturated infiltration } \\
\text { coefficient }\left(10^{-6} \mathrm{~m} / \mathrm{s}\right)\end{array}$} & \multicolumn{4}{|c|}{$\begin{array}{l}\text { Index of mechanical } \\
\text { property }\end{array}$} \\
\hline & & & & & \multicolumn{2}{|c|}{ Natural } & \multicolumn{2}{|c|}{ Saturated } \\
\hline & & & & & $\begin{array}{l}\mathrm{c} \\
(\mathrm{kPa})\end{array}$ & $\begin{array}{l}\Phi \\
\left({ }^{\circ}\right)\end{array}$ & $\begin{array}{l}\mathrm{c} \\
(\mathrm{kPa})\end{array}$ & $\begin{array}{l}\Phi \\
\left({ }^{\circ}\right)\end{array}$ \\
\hline Slip zone soil & 22 & 22.5 & 27.8 & 2 & 16.5 & 10.0 & 8.9 & 7.1 \\
\hline $\begin{array}{l}\text { Layers in fractured } \\
\text { sandstone }\end{array}$ & 24.6 & 25 & 24.3 & 35 & 42 & 18 & 38 & 14.6 \\
\hline $\begin{array}{l}\text { Interbedding layer } \\
\text { between shale and } \\
\text { sandstone }\end{array}$ & - & - & - & - & 40 & 18 & 35.7 & 14.6 \\
\hline
\end{tabular}

- Scenario A: Natural slope conditions without rainfall.

- Scenario B: 20-year return period for a 10-day rainfall period (320 mm).

- Scenario C: 50-year return period for a 10-day rainfall period $(370 \mathrm{~mm})$.

- Scenario D: 100-year return period for a 10-day rainfall period $(410 \mathrm{~mm})$.

The Finite Element SEEP/W module in the Geo-Studio software was used to calculate the matrix suction/pore water pressure profile of the slope under different rainfall scenarios. The rainfall boundary functions are imported on the surface of the slope. We then set the pore water pressure conditions as the parent analysis of SLOPE/W module for limit equilibrium analyses. The auto locate function in SLOPE/W was used to find the critical slip surface, and the Morgenstern and Price method was used to evaluate the factor of safety of the slope for each scenario (Fig. 8). With the geotechnical parameters established (Table 1), we calculated the slope stability and probability of failure and obtained the results listed in Table 2.

In Table 2, the slope stabilities and failure probabilities indicate that the post-slide slope remains stable in scenarios $\mathrm{A}$ and $\mathrm{B}$, but becomes unstable when it encounters the 50 -year extreme rainfall (scenario C). For scenario D, the slope becomes quite unstable with a low slope stability of 0.923 and a high failure probability of $98.5 \%$, which is the most dangerous scenario for slope failure. Rainfall is the main factor that influences the calculated slope stabilities and failure probabilities.

The post-slide slope, with its permeable, porous landslide deposits is ideally suited to rainfall infiltration and storage under conditions of prolonged, continuous rainfall. The infiltration of rainfall over 10 days will markedly destabilize the slope mass and result in the reduction of its mechanical strength, eventually culminating in slope 
Fig. 8 Calculated model of the post-slide 2013 Sunjia landslide slope referred to geological profile $5-5^{\prime}$. a The contour of pore water pressure and the seepage line (blue line) in the slope. b Slip surface associated with rainfall scenario D
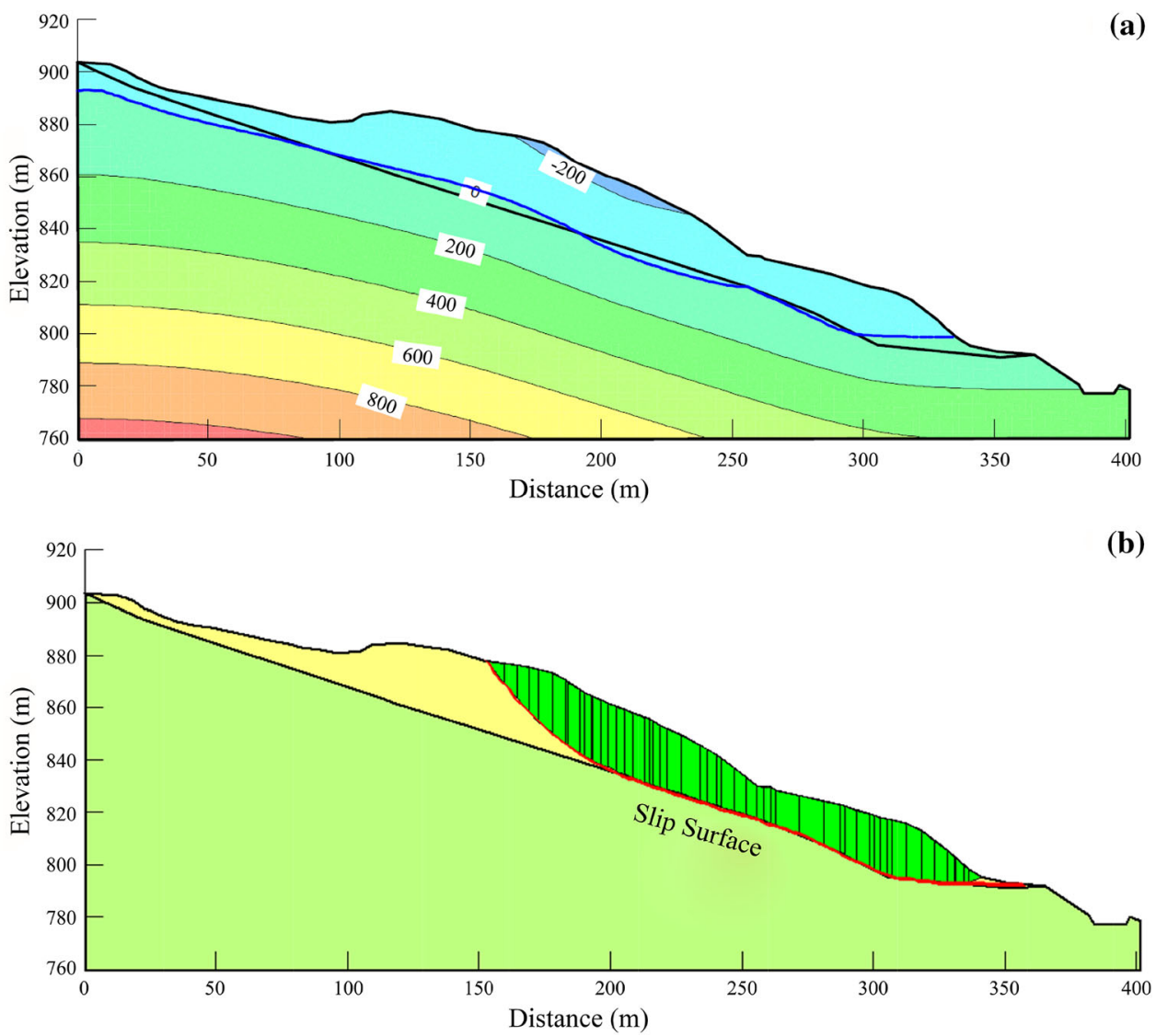

Table 2 Slope stability and probability of failure for the four scenarios

\begin{tabular}{lllr}
\hline Scenarios & Description & Stability $\left(\mathrm{F}_{\mathrm{s}}\right)$ & Probability of failure $\left(\mathrm{P}_{\mathrm{f}}\right)(\%)$ \\
\hline A & Natural slope conditions without rainfall & 1.397 & 0 \\
B & 20-year return period rainfall for 10 days & 1.142 & 8.2 \\
C & 50-year return period rainfall for 10 days & 1.012 & 21.4 \\
D & 100-year return period rainfall for 10 days & 0.923 & 98.5 \\
\hline
\end{tabular}

failure (Goodman and Kieffer 2000). We take the most dangerous scenario D to calculate the temporal probability and evaluate the risk of the post-slide slope.

\subsection{Post-Landslide Runout Analysis-Spatial Probability}

Potential runout movement is a key factor for landslide intensity and spatial probability evaluations (Crosta et al. 2003; Conte et al. 2019). Spatial probability describes the probability of a hazard event with a certain intensity at a particular location. As indicated in the temporal probability analysis, the 100-year return period of extreme rainfall would likely generate a failure of the post-landslide slope. To evaluate the potential consequences of this, we applied the Tsunami Squares (TS) (Wang et al. 2015, 2019; Xiao et al. 2015; Xiao et al. 2018) method to simulate the landslide movements considering the extreme rainfall scenario D. Having evolved from the parent method "Tsunami Balls" (Ward and Day 2006, 2008, 2010), the TS method inherits advantages of not needing a specialized computational mesh and obviates the need for millions of individual particles. This method advances the simulation of landslide movements with high accuracy on a laptop computer and can be extended to large spatial scales.

To simulate the runout movements, we first reconstructed the $3 \mathrm{D}$ geometry of the landslide with a volume of $1.0 \times 10^{6} \mathrm{~m}^{3}$ based on the topography map and borehole data. Ranging $700 \mathrm{~m}$ east to west and $1510 \mathrm{~m}$ north to south, the TS simulation comprises $350 \times 755$ squares 


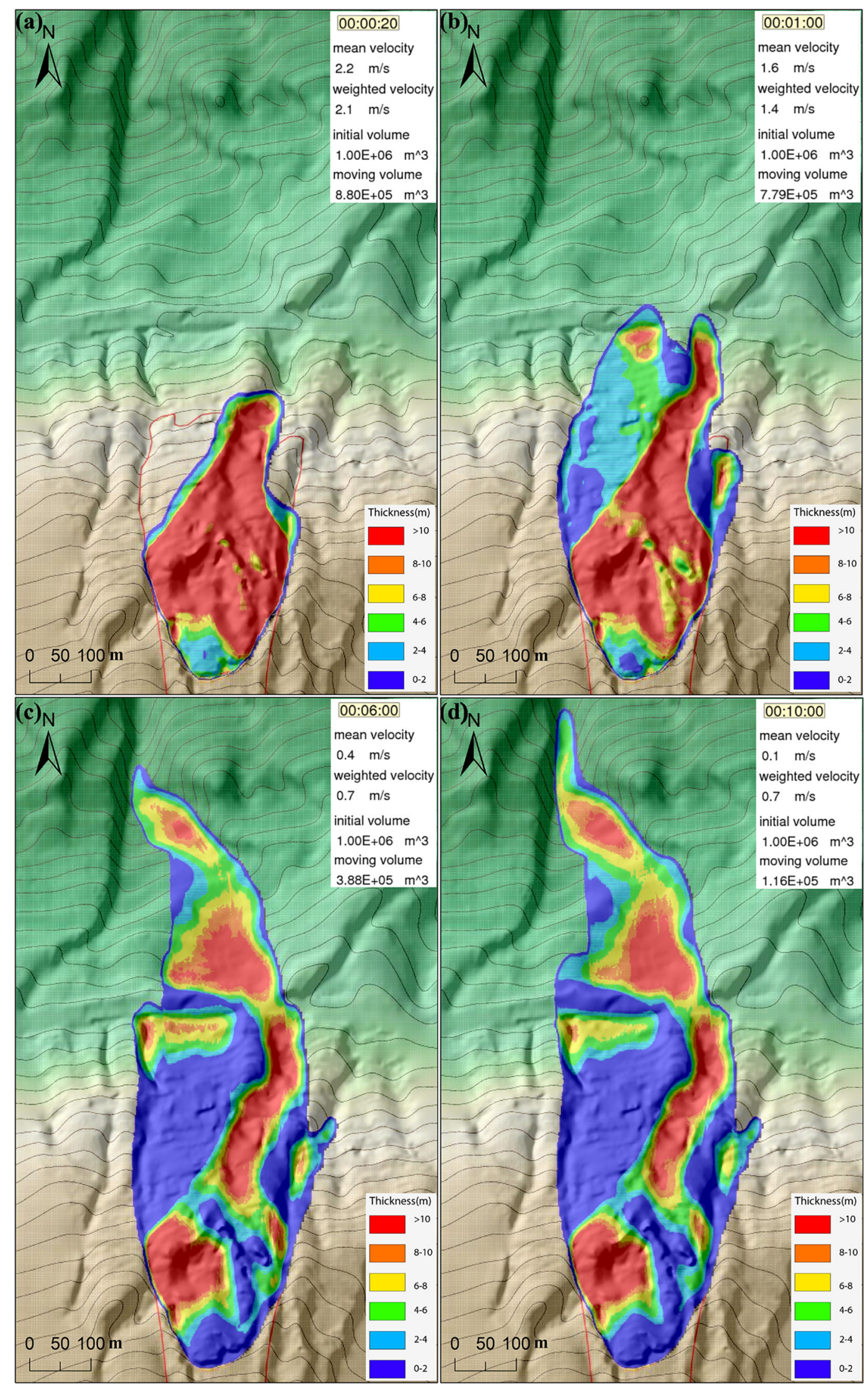


4Fig. 9 Simulation results of the 2013 Sunjia landslide in Wanzhou County. The rainbow color system in panels a-d describes the thickness of the moving materials. The white box in the upper-right corner of each panel quantifies aspects of the moving landslide. From top to bottom, they are: time, mean velocity, weighted velocity, initial volume, and moving volume

with a dimension $(D c)$ of $2 \mathrm{~m}$. The time step interval ( $\Delta t=0.5 \mathrm{~s}$ ) obeys the law that maximum displacement of a single square in a one-time step is no more than dimension $D_{c}$. The TS method applies basal and dynamic frictions to constrain the landslide speeds. We set the dynamic friction coefficient to be 0.5 while the basal friction coefficient varies from 0.05 to 1.5 due to the topography of the sliding surface and associated with the rock and soil mass parameters in Table 1.

Given the model setup, we ran TS and obtained time slices of the simulated runout dynamics of the post-landslide. Figure 9 shows landslide dynamics at four typical moments. Within 20 s after landslide initiation, most of the fractured rock and soil mass moves along the central gully and accumulates in the two-stage quarry (Fig. 9a). Between 1 and $2 \mathrm{~min}$, the left and middle part of the sliding body reaches the Yuwan expressway and rushes across it to a relatively gentle terrace below (Fig. 9b). The fractured rock beneath the drum hill is blocked by fracture L22, but most of the overlying debris is swept over the boundary and continues moving downwards toward the expressway as a thin flow. A small part of the sliding body runs along the gully on the right side and quickly stops nearby. From two to $10 \mathrm{~min}$, most of the sliding mass gathers and stops at the lower platform of the Yuwan expressway. However, some fragments continue to slide down the gully and end up at another gentle terrace (Fig. 9c, d). Tsunami Squares records maximum landslide velocities and thicknesses at any location during the movements. Figure 10 maps the maximum velocities and thicknesses at each element at risk, such as residential buildings, road networks, and land resources, which provides basic input data for the quantitative assessment of landslide vulnerability and risk.

\subsection{Post-Landslide Risk Analysis}

In the framework of landslide risk assessment, risk is the product of landslide hazard, vulnerability, and the elements at risk (Glade et al. 2005; Westen et al. 2006; Cascini 2008; Corominas and Moya 2008; Fell et al. 2008). Hazard is the probability of occurrence of a particular landslide within a
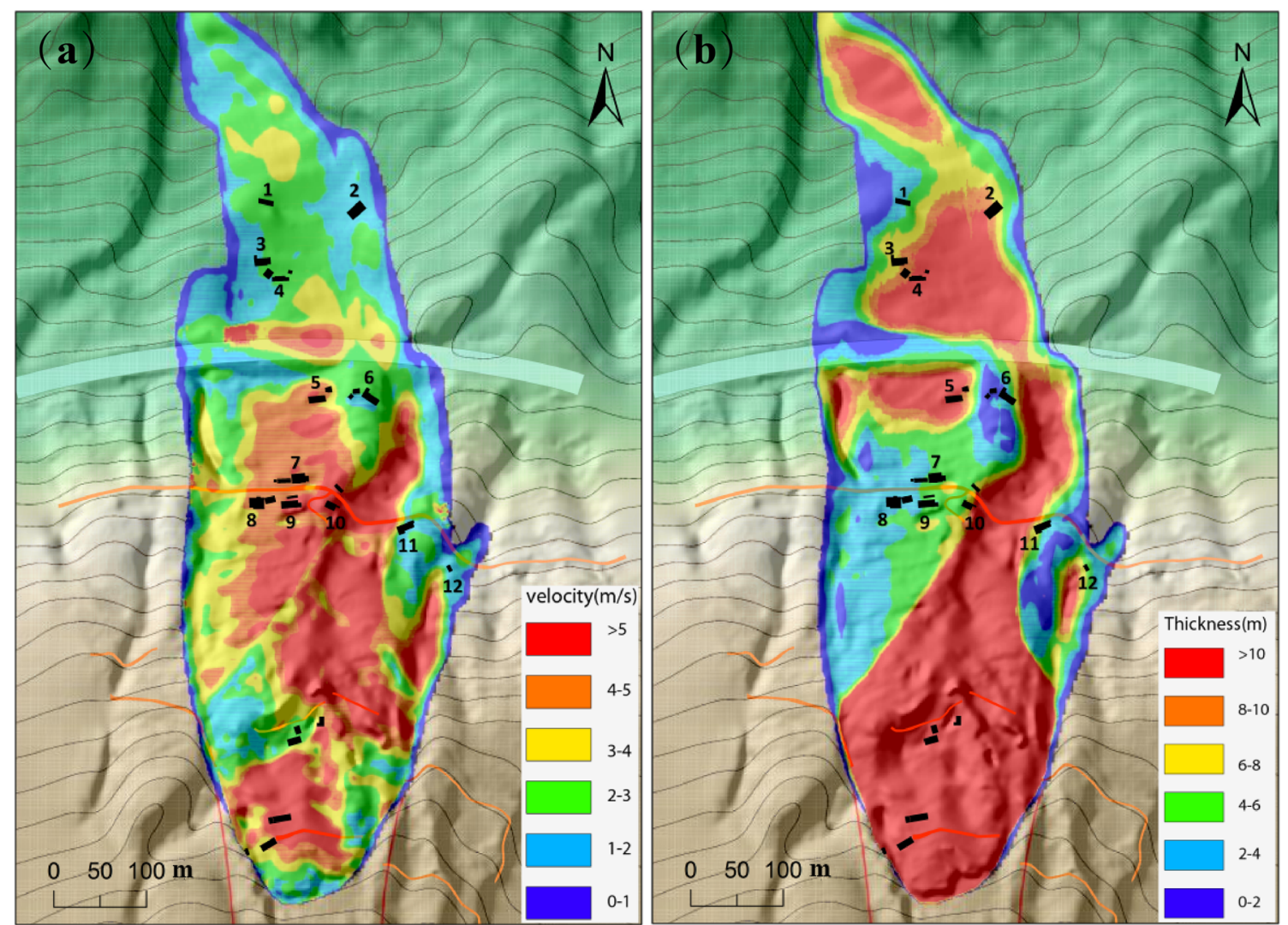

Fig. 10 Simulation results of the 2013 Sunjia landslide in Wanzhou County. a Map of the maximum landslide velocities. b Map of the maximum landslide thickness. The numbered black polygons mark the locations of the residential buildings 
specified period of time and within a given area. Vulnerability is the degree of loss of the elements at risk (a coefficient between 0 and 1). Exposure is a quantification of the elements at risk, including the total number of elements at risk and their economic value (Westen et al. 2006)

RISK $=$ HAZARD $*$ VULNERABILITY $*$ EXPOSURE

The probability of the hazard is evaluated separately or jointly by spatial, temporal, and magnitude probability (Westen et al. 2008). In this study, we evaluate landslide hazard as a joint probability of temporal and spatial probabilities under the conditions of extreme rainfall outlined in scenario D (100-year return period rainfall for 10 days) that would trigger the slope failure with a magnitude simulated by the Tsunami Squares method. The annual probability (temporal probability) of such a landslide is therefore $P_{h}=0.01 \times 0.985=0.00,985$.

Based on comparative analysis of high-resolution aerial images and auxiliary ground surveys, we extracted and

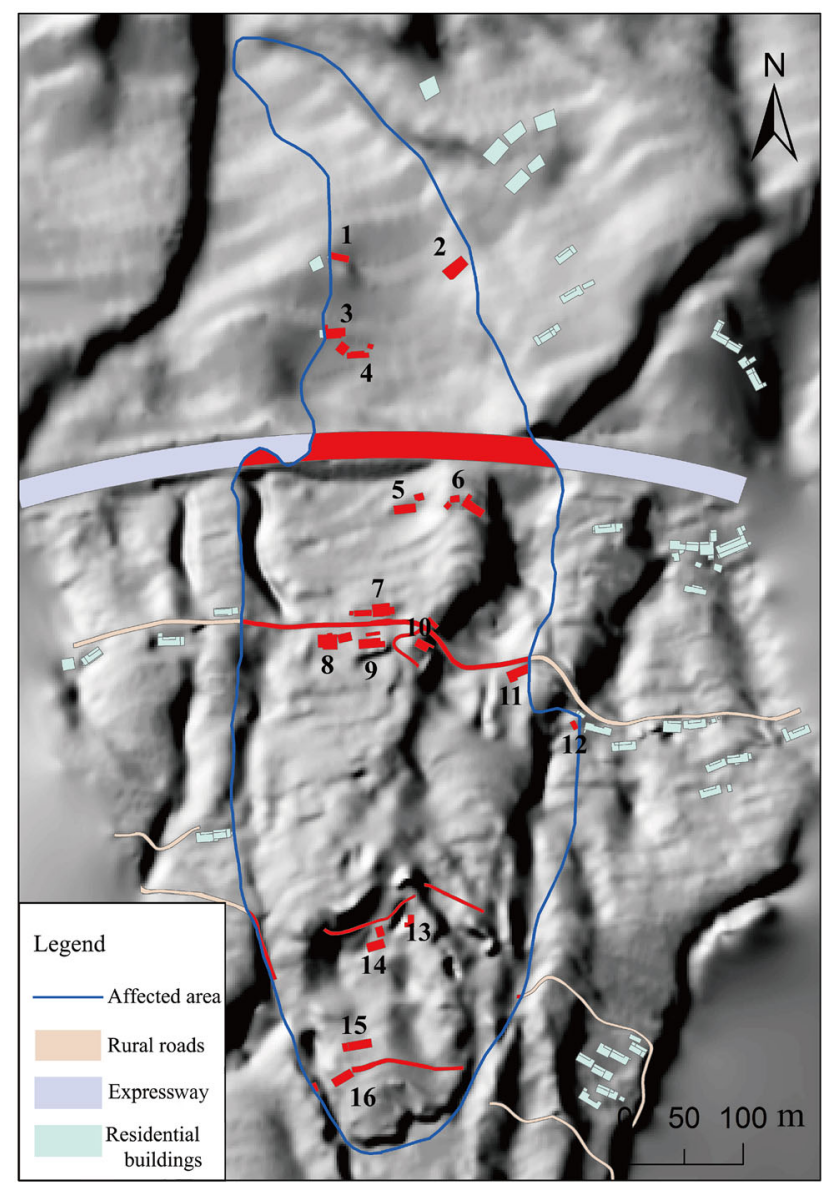

Fig. 11 The elements at risk in the 2013 Sunjia landslide in the Wanzhou County study area. The numbers indicate the houses at risk classified the elements at risk as population, residential buildings, road networks, and land resources. Figure 11 shows the distribution of the residential buildings and traffic routes in the study area.

Field investigations show that the affected area includes 12 houses with a total building area of $2158 \mathrm{~m}^{2}$. The people who had previously lived in the four dilapidated houses (Fig. 11, numbers 13-16) at the back margin of the landslide had been relocated to a safe place. The structure of the residential buildings is mainly brick-concrete with generally two floors. There are three main types of traffic routes in the study area: expressway, county roads, and rural roads. The main types of land resources in the landslide area are economic crops and forests, with an area of about $80,000 \mathrm{~m}^{3}$ and $\sim 2800$ trees, respectively. Summating the value of all the elements at risk as shown in Table 3, the potential total economic value of all of the elements at risk is about 4.57 million dollars. To estimate the number of casualties, we take into account the residents living inside the landslide area and the number of people on the highway and rural roads. Considering the information in Table 3, 42 permanent residents live in the landslide area. The number of people on the highway and rural roads are estimated to be 25 over a 1 -min period. Therefore, the total population at risk amounts to about 67 people.

Quantitative vulnerability analysis should consider the landslide intensity and the resistance capacity of the elements at risk (Uzielli et al. 2008). Here, we apply the vulnerability model (Eq. 9) proposed by Wang et al. (2015) to quantify the vulnerability of the elements involved in the Sunjia landslide.

$V_{\mathrm{s}}= \begin{cases}\frac{W}{Q}, & W \leq Q \\ 1, & W>Q\end{cases}$

where $V_{s}$ is the vulnerability of the elements at risk, $W$ is the intensity of the landslide (quantified by landslide impact force per unit-area), and $Q$ is the limit impact resistance capacity of the elements at risk (such as residential buildings, roads, and land resources) that they can sustain. Valentine (1998) stipulated that landslide impact pressure on the structures at a specific site is a function of landslide velocity $v$ and mass density $\rho$ :

$W=\frac{1}{2} \rho \cdot v^{2}$

In our model, landslide velocity can be obtained from the simulation of landslide runout dynamics shown in Fig. 10a. We estimated the mass density to be $2.5 \times 10^{3}$ $\left(\mathrm{kg} / \mathrm{m}^{3}\right)$ according to the parameters in Table 1. Based on the structure properties, we estimated the limit impact resistance pressure of the residential buildings (Tables 3,4) with respect to the limit value of the horizontal impact 
Table 3 Statistical data of the elements at risk derived from field surveys (unit of value: USD) in the 2013 Sunjia landslide study area in Wanzhou County

\begin{tabular}{|c|c|c|c|c|c|c|c|}
\hline \multirow{3}{*}{$\begin{array}{l}\text { Elements at risk } \\
\begin{array}{l}\text { Residential } \\
\text { buildings }\end{array}\end{array}$} & \multicolumn{7}{|c|}{ Properties of the elements at risk } \\
\hline & Number & 1 & 2 & 3 & 4 & 5 & 6 \\
\hline & Structure & $\begin{array}{l}\text { Brick- } \\
\text { concrete }\end{array}$ & $\begin{array}{l}\text { Brick- } \\
\text { concrete }\end{array}$ & $\begin{array}{l}\text { Brick- } \\
\text { concrete }\end{array}$ & $\begin{array}{l}\text { Brick- } \\
\text { concrete }\end{array}$ & $\begin{array}{l}\text { Brick- } \\
\text { concrete }\end{array}$ & $\begin{array}{l}\text { Brick- } \\
\text { concrete }\end{array}$ \\
\hline & Floor & 1 & 2 & 2 & 1 & 2 & 2 \\
\hline & Area $\left(\mathrm{m}^{2}\right)$ & 94 & 217 & 160 & 200 & 180 & 226 \\
\hline & Property indoor & 4470 & 4470 & 4470 & 4470 & 4470 & 4470 \\
\hline & Cost value & 8940 & 11,920 & 11,920 & 8940 & 11,920 & 11,920 \\
\hline & Population & 4 & 4 & 3 & 4 & 3 & 3 \\
\hline & $\begin{array}{l}\text { Limit impact resistance } \\
(\mathrm{KPa})\end{array}$ & 11.5 & 12.6 & 10.2 & 10.2 & 11.5 & 11.5 \\
\hline & Number & 7 & 8 & 9 & 10 & 11 & 12 \\
\hline & Structure & $\begin{array}{l}\text { Brick- } \\
\text { concrete }\end{array}$ & $\begin{array}{l}\text { Brick- } \\
\text { concrete }\end{array}$ & $\begin{array}{l}\text { Brick- } \\
\text { concrete }\end{array}$ & $\begin{array}{l}\text { Brick- } \\
\text { concrete }\end{array}$ & $\begin{array}{l}\text { Brick- } \\
\text { concrete }\end{array}$ & $\begin{array}{l}\text { Brick- } \\
\text { concrete }\end{array}$ \\
\hline & Floor & 3 & 3 & 3 & 2 & 2 & 1 \\
\hline & Area $\left(\mathrm{m}^{2}\right)$ & 262 & 282 & 200 & 140 & 152 & 45 \\
\hline & Property indoor & 5215 & 5215 & 5215 & 4470 & 4470 & 2980 \\
\hline & Cost value & 14,900 & 14,900 & 14,900 & 11,920 & 11,920 & 5960 \\
\hline & Population & 3 & 4 & 5 & 4 & 4 & 1 \\
\hline & $\begin{array}{l}\text { Limit impact resistance } \\
\quad(\mathrm{KPa})\end{array}$ & 12.6 & 12.6 & 12.8 & 11.4 & 9.6 & 8.7 \\
\hline & \multicolumn{2}{|l|}{ Road grade } & \multicolumn{2}{|c|}{ Expressway } & \multicolumn{2}{|c|}{ Country roads } & Rural roads \\
\hline \multirow[t]{9}{*}{ Road networks } & \multicolumn{2}{|c|}{ Impacted length (m) } & \multicolumn{2}{|l|}{300} & \multicolumn{2}{|l|}{400} & 600 \\
\hline & \multicolumn{2}{|l|}{ Width (m) } & 40 & & \multicolumn{2}{|l|}{8} & 5 \\
\hline & \multicolumn{2}{|l|}{ Unit price } & 298 & & \multicolumn{2}{|l|}{149} & 8.94 \\
\hline & \multicolumn{2}{|l|}{ Total price } & 3576,000 & & 476,800 & & 26,820 \\
\hline & Traffic flow & & & & & & \\
\hline & Flow/min & & 8 & & 0.1 & & 0 \\
\hline & Cost value & & 238,400 & & 1490 & & 0 \\
\hline & People & & 24 & & 1 & & 0 \\
\hline & & Type & & Cultivat & land & & Forest land \\
\hline Land resources & & Amount & & $80,000 \mathrm{r}$ & & & 2800 trees \\
\hline & & Unit price & & 372.5 & & & 4.47 \\
\hline & & Total price & & 44,700 & & & 12,516 \\
\hline
\end{tabular}

resistance of buildings with different masonry structure types calculated by $\mathrm{Du}$ (2012). Li et al. (2010) developed a model to describe the functional relationship between the vulnerability of people $\left(V_{p}\right)$ in a building and the vulnerability of the building $\left(V_{s}\right)$ by statistically analyzing the relationship between the vulnerability of buildings in various natural hazard-induced disasters and the proportion of casualties in them.

$V_{p}=0.001 \cdot \exp \left(\alpha \cdot V_{s}\right)$

where $V_{p}$ is the vulnerability of people inside the building, $V_{s}$ is the vulnerability of the building, and $\alpha$ is a constant factor that corresponds to a specific structure type. For masonry structures, $\alpha=6.1$ (Du 2012).

Based on landslide hazard analysis (temporal and spatial probabilities), we apply Eqs. 8 to 11 to evaluate the vulnerability and risk (Table 4) of the endangered elements (Table 3). Based on the simulated landslide runout (Fig. 10b), the maximum thickness of the landslide deposits that cover the Yuwan expressway is about 4-10 m. This $300 \mathrm{~m}$ section can be classified as a seriously hazardous area where the roadbed may crack and collapse, requiring large-scale specialized repairs. Therefore, the vulnerability of the affected section of the Yuwan 
Table 4 Results of vulnerability and risk assessment of elements at risk (unit of value: million USD) in the 2013 Sunjia landslide in Wanzhou County

\begin{tabular}{|c|c|c|c|c|c|c|c|c|c|c|c|c|}
\hline \multicolumn{13}{|l|}{ Vulnerability of residential buildings } \\
\hline Residential building number & 1 & 2 & 3 & 4 & 5 & 6 & 7 & 8 & 9 & 10 & 11 & 12 \\
\hline Landslide velocity (m/s) & 2.5 & 1.5 & 1.5 & 2.5 & 4.5 & 2 & 4 & 3.5 & 4.5 & 5 & 1.5 & 1 \\
\hline Landslide impact force $W(\mathrm{kPa})$ & 6.25 & 2.25 & 2.25 & 6.25 & 20.25 & 4 & 16 & 12.25 & 20.25 & 25 & 2.25 & 1 \\
\hline Limit impact resistance $Q(\mathrm{kPa})$ & 11.5 & 12.6 & 10.2 & 10.2 & 11.5 & 11.5 & 12.6 & 12.6 & 12.8 & 11.4 & 9.6 & 8.7 \\
\hline Vulnerability of buildings $V_{s}$ & 0.54 & 0.18 & 0.22 & 0.61 & 1 & 0.35 & 1 & 0.97 & 1 & 1 & 0.23 & 0.11 \\
\hline \multicolumn{13}{|c|}{ Vulnerability of people, $V p=0.001 \cdot \exp \left(\alpha \cdot V_{s}\right), \alpha=6.1$} \\
\hline People inside house & 0.027 & 0.003 & 0.004 & 0.041 & 0.446 & 0.008 & 0.446 & 0.371 & 0.446 & 0.446 & 0.004 & 0.002 \\
\hline People in vehicles & 1 & & & & & & & & & & & \\
\hline
\end{tabular}

Vulnerability of road networks and land resources

\begin{tabular}{llll}
\hline Expressway & Country roads & Rural roads & Land resources \\
\hline 0.85 & 1 & 1 & 0.9 \\
\hline
\end{tabular}

Quantitative risk of people $\left(R_{p}=P_{h} * V_{p} * N_{p}, P_{h}=0.985\right)$

\begin{tabular}{llll}
\hline People in vehicles & People inside house & Total risk in 100 years & Annual risk \\
\hline 24.6 & 8.4 & 33 & 0.33
\end{tabular}

Quantitative risk of residential buildings, road networks, and land resources $\left(R_{p}=P_{h}{ }^{*} V_{e} * N_{e}, P_{h}=0.985\right)$

\begin{tabular}{lllll}
\hline Road networks & Residential buildings & Land resources & Total risk in 100 years & Annual risk \\
\hline 3.691 & 0.125 & 0.051 & 3.867 & 0.0387 \\
\hline
\end{tabular}

expressway is defined as 0.85 . As the land resources and the low-grade roads could be severely damaged by the disaster, we defined their vulnerabilities to be 0.9 and 1 . We can estimate an approximate number of people under threat, but the temporal and spatial probabilities of the population are hard to assess, varying significantly between day and night. We assume that everyone is at home when calculating the vulnerability of permanent residents. We also assume that the vulnerability of people in vehicles is 1 . Table 4 lists all the results of landslide intensity, vulnerability, and risk assessment of elements at risk of the Sunjia landslide.

By adopting the above procedures of landslide risk assessment and taking the most dangerous scenario into account, we obtained the total number of casualties in a 100-year rainfall event (scenario D) to be 33 people, and a total economic loss of USD 3.867 million (Table 4). If calculated in an annual view, the annual risk of human casualties is 0.33 person per year ( 1 person per 3 years) and the annual risk of economic loss is USD 0.0387 million. These risk values can be used as a reference for public decisions by comparing them with the accepted or tolerated risk in the study area. They also provide basic data for the government to undertake appropriate landslide mitigation.

\section{Discussion}

The complexities of risk analysis of rainfall-induced landslides are reflected in many aspects, including hazard probability, hazard intensity, exposure, and the vulnerability of elements at risk.

For rainfall-induced landslides, the probability calculation ties to the return period of a specific triggering rainfall pattern and related slope stabilities and failure probabilities. These require statistical analysis of a large amount of historical data. Rainfall threshold analysis is a common approach for regional landslide hazard assessment and many case studies have been presented to correlate the landslide occurrence with statistical thresholds (Martelloni et al. 2012; Kanungo and Sharma 2013; Segoni et al. 2015). Rainfall threshold analysis may provide basic support for early warning of potential hazards, but it still cannot produce hazard probability of individual landslides (Capparelli and Versace 2014). Many researchers have proposed backanalysis of rainfall-induced slope failure by using numerical methods, taking into account the exact prolonged rainfall that triggered the event (Rahardjo et al. 2010; Harris et al. 2012). That approach could facilitate the establishment and development of an early warning system 
of rainfall-induced landslides; however, it cannot be used to carry out a long-term hazard probability prediction due to the shortage of lengthy historical rainfall records (Harris et al. 2012). As a result, reliable calculations of hazard probability of rainfall-induced landslides rarely appear in the literature. By contrast, our study, collected and comprehensively analyzed 50-year historical rainfall records in Wanzhou County. These enabled the calculation of the return period and probability of a particular rainfall pattern and the evaluation of the temporal probability of landslide of the post-slide Sunjia slope.

Landslide hazard intensity is difficult to obtain because of the complexity in modeling and predicting landslide deformation and movements. Simplified methods based on approximate assumptions are usually applied in the prediction of hazard intensity (displacement) for slow-moving landslides (Corominas et al. 2005; Ranalli et al. 2010). Those methods relate landslide movements to rain recordings and require a limited number of parameters as input data, many of which can be obtained from conventional geotechnical tests (Conte et al. 2017). Numerical solutions based on the finite element method or the finite difference method can provide a better understanding of the complex mechanisms of slope deformation (Lollino et al. 2010). Numerical methods such as DAN3D (Hungr and McDougall 2009), LS-RAPID (Sassa et al. 2010), and MassFlow (Ouyang et al. 2013), however, are costly from a computational viewpoint. In addition, a significant number of material parameters need to be evaluated in advanced constitutive models (Vassallo et al. 2015). In this study, the newly developed TS method (Wang et al. 2015, 2019; Xiao et al. 2015; Xiao et al. 2018) greatly contributed to the derivation of the landslide intensity including the velocity, thickness, runout distance, and impact area at each location of elements at risk.

Qualitative and semiquantitative vulnerability analysis approaches have been proposed since the early 1990s, however, they cannot support a quantitative landslide risk assessment (Panizza 1996; Finlay and Fell 1997). Quantitative risk assessment requires a quantitative vulnerability analysis that takes into account landslide intensity, fragility of elements at risk, as well as the interactions of structural mechanics and impact dynamics between the landslide and elements under threat (Uzielli et al. 2008; Li et al. 2010). In our study, we proposed a fully quantitative vulnerability model that incorporates landslide intensity and fragility of elements at risk from a force and energy point of view. Comparison of force and energy between landslides and elements at risk is the most direct description of vulnerability (Wang 2015). A thorough investigation of the elements at risk, as we have done in this study (Table 3), is urgently needed.
We chose not to analyze the sensitivity of the slope stability and landslide runout on the final risk. Instead, we took the most dangerous scenario to generate a particular risk calculation. In addition, the risk calculation did not pay attention to factors of post-disaster reconstruction, such as the environment's recovery, the mental health of the injured and displaced, and the long-term social impact. Although various methods to carry out quantitative landslide risk analysis are available, the applicability of these methods are still unsatisfactory and mostly dependent on the integrity and accuracy of the data investigated with respect to a specific landslide. Our study, however, connected all of those approaches in a case study by filling in the missing parts guided by a general framework for a fully-quantitative landslide risk assessment.

\section{Conclusion}

This study presented the physiography and geological characteristics, deformation mechanisms, and a quantitative risk analysis of the post-slide Sunjia slope. In consideration of the unstable state of the post-slide slope as indicated by post-event emergency monitoring, we carried out a quantitative risk analysis of the reactivation of the Sunjia landslide. We calculated a lower slope stability of 0.923 and a failure probability of $98.5 \%$ of the unstable post-slide slope given a scenario of a 100-year return period rainfall for 10 days. The Tsunami Squares method was applied to simulate the runout distance of the potential slope failure under such a situation. Making use of the hazard probability, landslide intensity, and vulnerabilities of the elements at risk, we quantitatively evaluated the risk of the post-slide slope of the Sunjia landslide. Under a 100-year return period rainfall (scenario D), the total population casualty of the Sunjia landslide is 33 people and the total economic loss is USD 3.867 million. This quantitative risk analysis of an individual rainfall-induced landslide provides a good example for landslide risk assessment and a technical route for hazard mitigation and prevention.

Acknowledgements This research is supported by the National Natural Science Foundation of China (Grant Numbers 41907234 and 41907237), the Natural Science Foundation of Shaanxi Province (Grant Number 2017JQ4010 and 2018JQ4041), the Postdoctoral Research Foundation of China (Grant Number 2017M613033), and the Fundamental Research Funds for the Central Universities, (Grant Numbers 300102210215, 300102210210, 300102219107 and 300102219104). We thank the Wanzhou Geological Environment Monitoring Station and the Nanjiang Hydrogeological Engineering Geological Team for providing us with valuable data. We also thank Prof. Kunlong Yin and Prof. Bo Chai from the China University of Geosciences and Prof. Steven N. Ward of the University of California, Santa Cruz for their significant contributions in improving this manuscript. 
Open Access This article is licensed under a Creative Commons Attribution 4.0 International License, which permits use, sharing, adaptation, distribution and reproduction in any medium or format, as long as you give appropriate credit to the original author(s) and the source, provide a link to the Creative Commons licence, and indicate if changes were made. The images or other third party material in this article are included in the article's Creative Commons licence, unless indicated otherwise in a credit line to the material. If material is not included in the article's Creative Commons licence and your intended use is not permitted by statutory regulation or exceeds the permitted use, you will need to obtain permission directly from the copyright holder. To view a copy of this licence, visit http://creativecommons. org/licenses/by/4.0/.

\section{References}

Andersson-Skold, Y., and L. Nyberg. 2016. Effective and sustainable flood and landslide risk reduction measures: An investigation of two assessment frameworks. International Journal of Disaster Risk Science 7(4): 374-392.

Baum, R.L., and J.W. Godt. 2010. Early warning of rainfall-induced shallow landslides and debris flows in the USA. Landslides 7(3): 259-272.

Beguería, S., and S.M. Vicente-Serrano. 2006. Mapping the hazard of extreme rainfall by peaks over threshold extreme value analysis and spatial regression techniques. Journal of Applied Meteorology and Climatology 45(1): 108-124.

Bell, R., and T. Glade. 2004. Quantitative risk analysis for landslides-Examples from Bíldudalur, NW-Iceland. Natural Hazards and Earth System Sciences 4(1): 117-131.

Bignami, D.F., A. Dragoni, and G. Menduni. 2018. Assessing and improving flood and landslide community social awareness and engagement via a web platform: The case of Italy. International Journal of Disaster Risk Science 9(4): 530-540.

Calvello, M., L. Cascini, and G.M. Grimaldi. 2009. Displacement scenarios of a rainfall-controlled slow moving active slide in stiff clays. Georisk Assessment and Management of Risk for Engineered Systems and Geohazards 3(3): 116-125.

Capparelli, G., and P. Versace. 2014. Analysis of landslide triggering conditions in the Sarno area using a physically based model. Hydrology and Earth System Sciences 18(8): 3225-3237.

Cascini, L. 2008. Applicability of landslide susceptibility and hazard zoning at different scales. Engineering Geology 102(3-4): 164-177.

Cascini, L., S. Cuomo, and M. Pastor. 2013. Inception of debris avalanches: Remarks on geomechanical modelling. Landslides 10(6): 701-711.

Conte, E., A. Donato, and A. Troncone. 2017. A simplified method for predicting rainfall-induced mobility of active landslides. Landslides 14(1): 35-45.

Conte, E., A. Donato, L. Pugliese, and A. Troncone. 2018. Analysis of the Maierato landslide (Calabria, Southern Italy). Landslides 15(10): 1935-1950.

Conte, E., L. Pugliese, and A. Troncone. 2019. Post-failure stage simulation of a landslide using the material point method. Engineering Geology 253: 149-159.

Corominas, J., and J. Moya. 2008. A review of assessing landslide frequency for hazard zoning purposes. Engineering Geology 102(3-4): 193-213.

Corominas, J., J. Moya, A. Ledesma, A. Lloret, and J.A. Gili. 2005. Prediction of ground displacements and velocities from groundwater level changes at the Vallcebre landslide (Eastern Pyrenees, Spain). Landslides 2(2): 83-96.
Crosta, G.B., S. Imposimato, and D.G. Roddeman. 2003. Numerical modelling of large landslide stability and runout. Natural Hazards and Earth System Sciences 3(6): 523-538.

Dai, F.C., C.F. Lee, and Y.Y. Ngai. 2002. Landslide risk assessment and management: An overview. Engineering Geology 64(1): $65-87$.

Deb, S.K., and A.I. El-Kadi. 2009. Susceptibility assessment of shallow landslides on Oahu, Hawaii, under extreme-rainfall events. Geomorphology 108(3-4): 219-233.

$\mathrm{Du}$, J. 2012. Risk assessment of individual landslide. PhD thesis. Wuhan: China University of Geosciences (in Chinese).

Duc, D.M. 2013. Rainfall-triggered large landslides on 15 December 2005 in Van Canh district, Binh Dinh province, Vietnam. Landslides 10(2): 219-230.

Fell, R. 1994. Landslide risk assessment and acceptable risk. Canadian Geotechnical Journal 31(2): 261-272.

Fell, R., J. Corominas, C. Bonnard, L. Cascini, E. Leroi, and W.Z. Savage. 2008. Guidelines for landslide susceptibility, hazard and risk zoning for land-use planning. Engineering Geology 102(3-4): 99-111.

Finlay, P.J., and R. Fell. 1997. Landslides: Risk perception and acceptance. Canadian Geotechnical Journal 34(2): 169-188.

Floris, M., and F. Bozzano. 2008. Evaluation of landslide reactivation: A modified rainfall threshold model based on historical records of rainfall and landslides. Geomorphology 94(1-2): 40-57.

Glade, T., M.G. Anderson, and M.J. Crozier. 2005. Landslide hazard and risk. London: Routledge.

Goodman, R.E., and D.S. Kieffer. 2000. Behavior of rock in slopes. Journal of Geotechnical and Geoenvironmental Engineering 126(8): 675-684.

Guzzetti, F., P. Reichenbach, F. Ardizzone, M. Cardinali, and M. Galli. 2006. Estimating the quality of landslide susceptibility models. Geomorphology 81(1-2): 166-184.

Harris, S.J., R.P. Orense, and K. Itoh. 2012. Back analyses of rainfallinduced slope failure in Northland Allochthon formation. Landslides 9(3): 349-356.

Hungr, O., and S. McDougall. 2009. Two numerical models for landslide dynamic analysis. Computers \& Geosciences 35(5): 978-992.

Iverson, R.M. 2000. Landslide triggering by rain infiltration. Water Resources Research 36(7): 1897-1910.

Kanungo, D.P., and S. Sharma. 2013. Rainfall thresholds for prediction of shallow landslides around Chamoli-Joshimath region, Garhwal Himalayas, India. Landslides 11(4): 629-638.

Krahn, J. 2008a. Stability modeling with SLOPE/W-An engineering methodology, 3rd edn. Calgary: GEO-SLOPE International Ltd.

Krahn, J. 2008b. Seepage modeling with SEEP/W-An engineering methodology, 3rd edn. Calgary: GEO-SLOPE International Ltd.

Li, Z.H., F. Nadim, H.W. Huang, M. Uzielli, and S. Lacasse. 2010. Quantitative vulnerability estimation for scenario-based landslide hazards. Landslides 7(2): 125-134.

Lin, F., L.Z. Wu, R.Q. Huang, and H. Zhang. 2018. Formation and characteristics of the Xiaoba landslide in Fuquan, Guizhou, China. Landslides 15(4): 669-681.

Lollino, P., G. Elia, F. Cotecchia, and G. Mitaritonna. 2010. Analysis of landslide reactivation mechanisms in Daunia clay slopes by means of limit equilibrium and FEM methods. In GeoFlorida 2010: Advances in Analysis, Modeling \& Design, Geotechnical Special Publication 199, ed. D.O. Fratta, A.J. Puppala, and B. Muhunthan, 3155-3164. Reston, VA: American Society of Civil Engineers.

Malamud, B.D., D.L. Turcotte, F. Guzzetti, and P. Reichenbach. 2004. Landslide inventories and their statistical properties. Earth Surface Processes and Landforms 29(6): 687-711. 
Martelloni, G., S. Segoni, R. Fanti, and F. Catani. 2012. Rainfall thresholds for the forecasting of landslide occurrence at regional scale. Landslides 9(4): 485-495.

Martha, T.R., P. Roy, K.B. Govindharaj, K.V. Kumar, P.G. Diwakar, and V.K. Dadhwal. 2015. Landslides triggered by the June 2013 extreme rainfall event in parts of Uttarakhand state, India. Landslides 12(1): 135-146.

Ndah, A.B., and J.O. Odihi. 2017. A systematic study of disaster risk in Brunei Darussalam and options for vulnerability-based disaster risk reduction. International Journal of Disaster Risk Science 9(2): 157-166.

Ouyang, C.J., S.M. He, Q. Xu, Y. Luo, and W.C. Zhang. 2013. A maccormack-tvd finite difference method to simulate the mass flow in mountainous terrain with variable computational domain. Computers \& Geosciences 52: 1-10.

Panizza, M. 1996. Environmental geomorphology. Amsterdam: Elsevier.

Rahardjo, H., A.S. Nio, E.C. Leong, and N.Y. Song. 2010. Effects of groundwater table position and soil properties on stability of slope during rainfall. Journal of Geotechnical and Geoenvironmental Engineering 136(11): 1555-1564.

Ranalli, M., G. Gottardi, Z. Medina-Cetina, and F. Nadim. 2010. Uncertainty quantification in the calibration of a dynamic viscoplastic model of slow slope movements. Landslides 7(1): $31-41$.

Sabatakakis, N., G. Koukis, and D. Mourtas 2005. Composite landslides induced by heavy rainfalls in suburban areas: City of Patras and surrounding area, western Greece. Landslides 2(3): 202-211.

Sassa, K., O. Nagai, R. Solidum, Y. Yamazaki, and H. Ohta. 2010. An integrated model simulating the initiation and motion of earthquake and rain induced rapid landslides and its application to the 2006 Leyte landslide. Landslides 7(3): 219-236.

Segoni S., D. Lagomarsino, R. Fanti, S. Moretti, and N. Casagli. 2015. Integration of rainfall thresholds and susceptibility maps in the Emilia Romagna (Italy) regional-scale landslide warning system. Landslides 12(4): 773-785.

Uzielli, M., F. Nadim, S. Lacasse, and A.M. Kaynia. 2008. A conceptual framework for quantitative estimation of physical vulnerability to landslides. Engineering Geology 102(3-4): 251-256.

Valentine, G.A. 1998. Damage to structures by pyroclastic flows and surges, inferred from nuclear weapons effects. Journal of Volcanology and Geothermal Research 87(1-4): 117-140.

Vassallo, R., G.M. Grimaldi, and C. Di Maio. 2015. Analysis of transient pore pressure distribution and safety factor of a slow clayey deep-seated landslide by 2D and 3D models. Engineering Geology for Society and Territory-Volume 2: Landslide Processes, ed. G. Lollino. D. Giordan. G.B. Crosta. J. Corominas, R. Azzam, J. Wasowski, and N. Sciarra, 2123-2127. Cham, Switzerland: Springer.
Westen, C.J. van, T.W. van Asch, and R. Soeters. 2006. Landslide hazard and risk zonation-Why is it still so difficult? Bulletin of Engineering Geology and the Environment 65(2): 167-184.

Westen, C.J. van, E. Castellanos, and S.L. Kuriakose. 2008. Spatial data for landslide susceptibility, hazard, and vulnerability assessment: An overview. Engineering Geology 102(3-4): $112-131$

Wang, J. 2015. Landslide risk assessment in Wanzhou County, Three Gorges Reservoir. PhD thesis. Wuhan: China University of Geosciences (in Chinese).

Wang, J., S.N. Ward, and L. Xiao. 2015. Numerical modelling of rapid, flow-like landslides across 3-D terrains: A Tsunami Squares approach to El Picacho landslide, El Salvador, September 19, 1982. Geophysical Journal International 201(3): $1534-1544$.

Wang, J., S.N. Ward, and L. Xiao. 2019. Tsunami squares modeling of landslide generated impulsive waves and its application to the 1792 Unzen-Mayuyama mega-slide in Japan. Engineering Geology 256: 121-137.

Wang, J., L. Xiao, J. Zhang, and Y.B. Zhu. 2020. Deformation characteristics and failure mechanisms of a rainfall-induced complex landslide in Wanzhou County, Three Gorges Reservoir, China. Landslides 17(2): 419-431.

Ward, S.N., and S. Day. 2006. Particulate kinematic simulations of debris avalanches: Interpretation of deposits and landslide seismic signals of Mount Saint Helens, 1980 May 18. Geophysical Journal International 167(2): 991-1004.

Ward, S.N., and S. Day. 2008. Tsunami balls: A granular approach to tsunami runup and inundation. Communications in Computational Physics 3(1): 222-249.

Ward, S.N., and S. Day. 2010. The 1958 Lituya Bay landslide and tsunami-A tsunami ball approach. Journal of Earthquake and Tsunami 4(4): 285-319.

Xiao, L., S.N. Ward, and J. Wang. 2015. Tsunami squares approach to landslide-generated waves: Application to Gongjiafang Landslide, Three Gorges Reservoir, China. Pure and Applied Geophysics 172(12): 3639-3654.

Xiao, L., J. Wang, S.N. Ward, and L. Chen. 2018. Numerical modeling of the June 24, 2015, Hongyanzi landslide generated impulse waves in Three Gorges Reservoir, China. Landslides 15(12): 2385-2398.

Xu, Q., X. Fan, and X. Dong. 2012. Characteristics and formation mechanism of a catastrophic rainfall-induced rock avalanchemud flow in Sichuan, China, 2010. Landslides 9(1): 143-154.

Xu, D., L. Peng, S. Liu, and X. Wang. 2018. Influences of risk perception and sense of place on landslide disaster preparedness in southwestern China. International Journal of Disaster Risk Science 9(2): 167-180.

Yue, S. 2001. The Gumbel logistic model for representing a multivariate storm event. Advances in Water Resources 24(2): 179-185. 